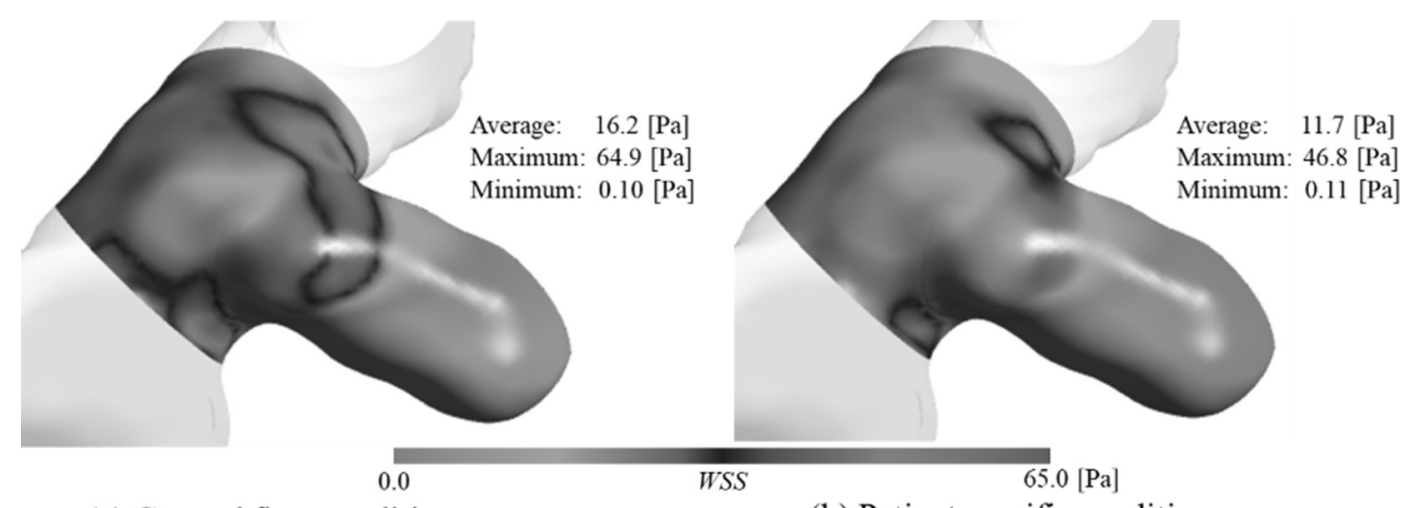

(a) General flow condition

(b) Patient specific condition

Abstract 0-022 Figure 1 Hemodynamic difference between general flow condition and patient specific condition

computational fluid dynamics (CFD). In previous studies, we have used the same inflow condition to simulate blood flow regardless of patients' differences, although the heartbeat cycle differed from patient to patient. In this study, we extracted the patient-specific heartbeat cycle and blood flow velocity from four-dimensional digital subtraction angiography (4DDSA) data that contain spatial and temporal information of contrast media. Finally, we performed CFD simulations and evaluated the effect of patient-specific inflow conditions.

Materials and methods Data of a 73-year-old man with hypertension were analyzed. We extracted the patient-specific heartbeat cycle and blood flow velocity from 4D-DSA data. Then, we performed CFD simulations using ANSYS CFX 18.1 under both general inflow conditions (healthy adult) and patient-specific inflow conditions extracted from 4D-DSA to reproduce the angiographic images. We calculated the cardiac cycle duration and the amplitude of voxel intensity values at one point on the vessel centerline over two cardiac cycles, for both the CFD simulation and 4D-DSA data sets. To assess the accuracy of the patient-specific flow condition extraction method, we compared the calculation results of the cardiac cycle duration and the amplitude obtained from both data sets. Finally, we compared the wall shear stress (WSS) differences caused between general inflow condition and patient-specific condition.

Results The 4D-DSA analysis gave a heartbeat cycle duration of $1.11 \mathrm{~s}$ and an intensity amplitude of 0.856 . The CFD simulation under general inflow condition gave a cycle duration of $0.825 \mathrm{~s}$, and an intensity amplitude of 0.879 . In contrast, the CFD simulation under patient-specific inflow condition gave a cycle duration of $1.03 \mathrm{~s}$ and an intensity amplitude of 0.854. The cycle duration error difference between 4D-DSA analysis and CFD simulation results under general inflow condition was $3.90 \%$, and between intensities $25.3 \%$. In contrast, the cycle duration error between 4D-DSA and CFD simulation under patient-specific condition was $0.945 \%$, and the intensity amplitude error $7.24 \%$. In addition, we found that the WSS value using general conditions was overestimated compared with that using patient-specific condition in this case (see figure 1).

Conclusions We performed CFD simulation using patient-specific heartbeat cycle and blood flow velocity extracted from 4D-DSA data. The result showed that the CFD simulation under patient-specific inflow condition could simulate the actual blood flow more accurately.

Disclosures H. Ohno: None. H. Takao: None. T. Suzuki: None. S. Fujimura: None. Y. Uchiyama: None. K. Tanaka:
None. T. Okudaira: None. T. Ishii: None. K. Otani: None. T. Ishibashi: None. K. Fukudome: None. M. Yamamoto: None. Y. Murayama: None.

\section{0-023 STENT-ASSISTED COILING OF CEREBRAL ANEURYSMS: MULTI-CENTER ANALYSIS OF RADIOGRAPHIC AND CLINICAL OUTCOMES IN 659 PATIENTS}

${ }^{1} \mathrm{M}$ Mokin* ${ }^{*}{ }^{1} \mathrm{C}$ Primiani, ${ }^{1} \mathrm{~K}$ Piper, ${ }^{2} \mathrm{D}$ Fiorella, ${ }^{3} \mathrm{~A}$ Rai, ${ }^{4} \mathrm{~K}$ Orlov, ${ }^{4} \mathrm{D}$ Kislitsin, ${ }^{4} \mathrm{~A}$ Gorbatykh, ${ }^{5} \mathrm{~J}$ Mocco, ${ }^{5} \mathrm{R}$ Deleacy, ${ }^{5} \mathrm{~J}$ Lee, ${ }^{6} \mathrm{~A}$ Spiotta, ${ }^{6} \mathrm{R}$ Turner, ${ }^{6} \mathrm{I}$ Chaudry, ${ }^{6} \mathrm{~A}$ Turk. ${ }^{1}$ Neurosurgery, University of South Florida, Tampa, FL; ${ }^{2}$ Cerebrovascular Center, State University of New York, Stony Brook, NY; ${ }^{3}$ Radiology, West Virginia University, Morgantown, WV ${ }^{4}$ Neurosurgery, Meshalkin National Medical Research Center, Novosibirsk, Russian Federation; ${ }^{5}$ Neurosurgery, Icahn School of Medicine at Mount Sinai, New York, NY; ${ }^{6}$ Neurosurgery, Medical University of South Carolina, Charleston, SC

\subsection{6/neurintsurg-2019-SNIS.23}

Introduction Endovascular stent-assisted coiling approach for the treatment of cerebral aneurysms is evolving rapidly with the availability of new stent devices. It remains unknown how each type of stent affects the safety and efficacy of the stentcoiling procedure.

Methods This study compared the outcomes of endovascular coiling of cerebral aneurysms using Neuroform (NEU), Enterprise (EP), and Low-profile Visualized Intraluminal Support (LVIS) stents. Patient characteristics, angiographic results using the Raymond-Roy grade scale (RRGS), clinical outcomes and procedural complications were analyzed in our study.

Results 659 patients with 670 cerebral aneurysms treated with stent-assisted coiling (NEU, $n=182$; EP, $n=158$; LVIS, $n=330$ ) were retrospectively collected from six academic centers. Patient characteristics included mean age $56.3 \pm 12.1$ years old, female prevalence $73.9 \%$ and aneurysm rupture on initial presentation of $18.8 \%$. We found differences in complete occlusion on baseline imaging, defined as RRGS I, among the three stents: LVIS 64.4\%, 210/326; NEU 56.2\%, 95/169; EP $47.6 \%, 68 / 143 ; \mathrm{p}=0.008$. The difference of complete occlusion on 10.5 months (mean) and 8 months (median) angiographic follow-up remained significant: LVIS 84\%, 251/299; NEU 78\%, 117/150; EP 67\%, 83/123; p=0.004. There were $7 \%$ (47/670) intra-procedural complications and $11.5 \%(73 /$ 632) post-procedural related complications in our cohort.

Conclusions The type of stent used for stent-assisted coiling affects immediate and long-term angiographic outcomes. Randomized prospective trials comparing the different types of stents are warranted. 
Disclosures M. Mokin: 2; C; Toshiba (Canon) Medical. C. Primiani: None. K. Piper: None. D. Fiorella: 1; C; reports grants, non-financial support, and other funding from Penumbra, Cerenovus, and Stryker; non-financial support and other funding from Genentech and Shape Memory Medical; and grants from Siemens. A. Rai: 6; C; reports other from Penumbra; and non-financial support from Microvention and Stryker. K. Orlov: None. D. Kislitsin: None. A. Gorbatykh: None. J. Mocco: 6; C; reports other from Penumbra, Cerebrotech, Rebound Therapeutics, TSP, Lazarus Effect, Medina, Pulsar Vascular, and Blockade. R. DeLeacy: 6; C; reports other and non-financial support from Penumbra; and non-financial support from Cerenovus and Siemens. J. Lee: None. A. Spiotta: 6; C; reports other and non-financial support from Penumbra, Pulsar Vascular, and Stryker and grants, other, and non-financial support from Microvention. R. Turner: 2; C; consultant for Penumbra, Medtronic, Microvention, Codman, Pulsar Vascular, Q'Apel, Rebound Medical, and Blockade Medical. I. Chaudry: 6; C; reports other, grants, and non-financial support from Penumbra and Pulsar Vascular; grants and nonfinancial support from Medtronic, Microvention, and Codman; non-financial support and other from Bloc. A. Turk: 6; C; reports other, grants, and non-financial support from Penumbra and Pulsar Vascular; grants and non-financial support from Codman, Microvention, and Medtronic; non-financial support and other from Bloc.

\section{0-024 COMPARISON BETWEEN OUTCOMES OF ANTERIOR AND POSTERIOR CEREBRAL CIRCULATION ANEURYSMS IN THE SMART REGISTRY COHORT}

E Almallouhi*, M Sattur, M Anadani, S Al kasab, A Spiotta. Medical University of South Carolina, Charleston, SC

\subsection{6/neurintsurg-2019-SNIS.24}

Background Endovascular treatment of cerebral aneurysms in the posterior circulation poses a challenge because of the higher rate of wide-necked aneurysms and presentation with rupture. In this study, we compare the baseline characteristics and outcomes of patients with posterior circulation aneurysms treated with novel second-generation coils in the SMART registry.

Methods SMART is a phase 4, multicenter, prospective, registry that enrolled patients with anterior and posterior circulation cerebral aneurysms (both ruptured and unruptured) who underwent endovascular treatment using Penumbra SMART ${ }^{\mathrm{TM}}$ Coils. Collected data included baseline clinical and angiographic characteristics at presentation. Primary and secondary end points were immediate angiographic occlusion, periprocedural complications, recanalization and retreatment rates and mortality at 1 -year follow up. We compared the above variables between anterior and posterior circulation aneurysms.

Results Of a total of 906 patients treated in the SMART registry, $173(19.1 \%)$ had posterior circulation aneurysms. In comparison to patients with anterior circulation aneurysms, patients with aneurysms in the posterior circulation were older (mean age 61.7 vs. 59.3 years, P 0.017 ) and more likely to present with rupture $(38.7 \%$ vs. $30.3 \%, \mathrm{P} 0.032)$. Posterior circulation aneurysms were more likely to be widenecked (defined as an aneurysm with a dome-to-neck ratio less than 2.0 and/or a neck length of $4 \mathrm{~mm}$ or more). No significant difference was found in the rate of successful embolization at initial procedure (Raymond Class I), serious device-related adverse effects within 24 hours, one-year recanalization and one-year retreatment between both groups (table 1).

\begin{tabular}{|c|c|c|c|}
\hline Baseline characteristics & $\begin{array}{l}\text { Posterior circulation } \\
\text { aneurysm patients } \\
(\mathrm{N}=173)\end{array}$ & $\begin{array}{l}\text { Anterior circulation } \\
\text { aneurysm patients } \\
(\mathrm{N}=733)\end{array}$ & $\begin{array}{l}P \text { - } \\
\text { value }\end{array}$ \\
\hline Age, Mean SD & 61.711 .6 & 59.312 .8 & 0.017 \\
\hline Female, $\%(\mathrm{n} / \mathrm{N})$ & $78.6 \%(136 / 173)$ & $73.9 \%(542 / 733)$ & 0.203 \\
\hline $\begin{array}{l}\text { Ruptured aneurysm, \% } \\
(\mathrm{n} / \mathrm{N})\end{array}$ & $38.7 \%(67 / 173)$ & $30.3 \%(222 / 733)$ & 0.032 \\
\hline Aneurysm Size \% (n/N) & & & 0.285 \\
\hline Small (<11mm) & $86.1 \%(149 / 173)$ & $89.5 \%$ (656/733) & \\
\hline Large (11 to $25 \mathrm{~mm}$ ) & $13.3 \%(23 / 173)$ & $10.4 \%(76 / 733)$ & \\
\hline Giant $(>25 \mathrm{~mm})$ & $0.6 \%(1 / 173)$ & $0.1 \%(1 / 733)$ & \\
\hline Wide-Neck\% (n/N) & $72.2 \%(117 / 162)$ & $59.9 \%(439 / 733)$ & 0.002 \\
\hline $\begin{array}{l}\text { Stent-Assisted Coiling \% (n/ } \\
\text { N) }\end{array}$ & $38.2 \%(66 / 173)$ & $36.2 \%(265 / 733)$ & 0.624 \\
\hline $\begin{array}{l}\text { Balloon-Assisted Coiling \% } \\
\text { (n/N) }\end{array}$ & $16.8 \%(29 / 173)$ & $20.6 \%(151 / 733)$ & 0.255 \\
\hline Raymond Occlusion, Class I & & & \\
\hline $\begin{array}{l}\text { Immediate Post-Procedure\% } \\
(\mathrm{n} / \mathrm{N})\end{array}$ & $37.6 \%(65 / 172)$ & $41.1 \%(298 / 729)$ & 0.457 \\
\hline $\begin{array}{l}\text { One-Year Follow-Up \% } \\
(\mathrm{n} / \mathrm{N})\end{array}$ & $55.1 \%(43 / 78)$ & $64.4 \%(250 / 388)$ & 0.121 \\
\hline $\begin{array}{l}\text { Recanalization at One-Year } \\
\text { Follow-Up \% (n/N) }\end{array}$ & $12.8 \%(10 / 78)$ & $14 \%(54 / 385)$ & 0.205 \\
\hline $\begin{array}{l}\text { Retreatment through } \\
\text { One-Year Follow-Up }\end{array}$ & $6.2 \%(5 / 81)$ & $7 \%(28 / 399)$ & 0.190 \\
\hline $\begin{array}{l}\text { Device-Related SAE within } \\
24 \text { Hours of Procedure \% } \\
(\mathrm{n} / \mathrm{N})\end{array}$ & $1.7 \%(3 / 173)$ & $3 \%(22 / 733)$ & 0.360 \\
\hline $\begin{array}{l}\text { Length of Hospital Stay, } \\
\text { Median [IQR] }\end{array}$ & $2[1-14]$ & $1[1-10]$ & 0.053 \\
\hline
\end{tabular}

Conclusions Despite being associated with higher rates of rupture and wide-necked geometry, patients with posterior circulation aneurysms experienced immediate and one-year angiographic occlusion rates that were not significantly different from anterior circulation aneurysms. Device-related periprocedural complications were also not significantly higher than the latter.

Disclosures E. Almallouhi: None. M. Sattur: None. M. Anadani: None. S. Al kasab: None. A. Spiotta: 2; C; Penumbra, Cerenovus, Minnetronix.

\section{0-025 SOUND MEASUREMENT IN PATIENT-SPECIFIC 3D PRINTED BENCH MODELS FOR VENOUS PULSATILE TINNITUS}

M Amans*, K Valluru, H Haraldsson, E Kao, J Leach, A Wright, M Ballweber, K Meisel, D Saloner. Radiology, UCSF, San Francisco, CA

\subsection{6/neurintsurg-2019-SNIS.25}

Introduction Pulsatile tinnitus (PT) can be caused by aberrant blood flow in large cerebral veins near the cochlea. In our previous works we evaluated flow patterns in patient's 